\title{
Epicardial fat, gender, and cardiovascular risk
}

\author{
Manuel Monti, ${ }^{1}$ Roberto Marchetti, ${ }^{2}$ Giovanni Maria Vincentelli ${ }^{2}$ \\ ${ }^{1}$ Emergency Department, AUSL UMBRIA1, Assisi (PG); ${ }^{2}$ Emergency Department, Fatebenefratelli Hospital, Isola Tiberina, \\ Roma, Italy
}

\begin{abstract}
Epicardial fat (EF) is considered an important risk factor and an active player in the pathogenesis of cardiovascular and metabolic diseases. EF is an endocrine organ that releases hormones and mediators, including the circulating C-reactive protein (CRP), and plays a vital role in modifying the vascular endothelial function and promoting the growth of coronary atherosclerosis. This study aimed to investigate the relationship between CRP concentrations and EF in a cohort of patients with metabolic syndrome at risk for coronary artery disease. In our study, carried out in primary prevention, we enrolled 36 subjects (M/F: 21/15; age: $59.3 \pm 0.79 \mathrm{yrs}$ ) diagnosed with metabolic syndrome. We have classified the patients into two groups: Men and Women. Besides anthropometric characterization and screening laboratory tests, the subjects performed a multidetector computed tomography scan, which allowed the EF quantification. Mean EF was $115.1 \mathrm{cc}$ in the study population. The average EF of women was $111 \mathrm{cc}$; the average EF of men was $118 \mathrm{cc}(\mathrm{P}=0.18)$. CRP levels were strongly positively correlated with EF area in women $(\mathrm{P}=0.01)$, while the correlation was not found in men $(\mathrm{P}=0.4)$. Our findings suggest that, in women, the EF produces a greater amount of acute-phase proteins and increases the pro-inflammatory state in the epicardial region. For this reason, we can hypothesize, in women, a different role in the development of atherosclerotic plaque of the epicardial fat compared to men.
\end{abstract}

\section{Introduction}

Epicardial fat (EF) is considered an essential independent cardiovascular risk factor and may contribute, through local production of inflammatory cytokine and the development of a chronic, low-grade inflammatory state, to the progression of coronary atherogenesis. ${ }^{1-3}$ Particularly, EF is the visceral fat depot with anatomical and functional contiguity to the myocardium. The EF has unique characteristics compared to others of visceral fat deposits, as it uses the same bloodstream of the myocardium and has a more

Correspondence: Manuel Monti, Emergency Department, USL UMBRIA1 U.O. PS/118, via V. Muller 1, Assisi (PG), Italy.

E-mail: montimanuel@tiscali.it

Key words: Epicardial fat; gender; C-reactive protein; cardiovascular diseases.

Conflict of interests: the authors declare no potential conflict of interests.

Received for publication: 29 July 2020.

Revision received: 1 February 2021.

Accepted for publication: 4 February 2021.

This work is licensed under a Creative Commons Attribution NonCommercial 4.0 License (CC BY-NC 4.0).

${ }^{\circ}$ Copyright: the Author(s), 2021

Licensee PAGEPress, Italy

Italian Journal of Medicine 2021; 15:93-98

doi:10.4081/itjm.2021.1349 remarkable ability to release free fatty acids (FFA), necessary for the myocardium to produce energy. ${ }^{4,5}$ Furthermore, the EF shows a greater expression and secretion of adipokines and inflammatory chemokines [tumor necrosis factor (TNF)-alpha, interleukin (IL)8, MCP-1, C-reactive protein (CRP), IL-1 $\beta$, and IL6] and infiltration of the chronic inflammatory cell as macrophage in pathological conditions. ${ }^{6}$ For these features, EF plays an important role in modifying the vascular endothelial function and promoting the growth of coronary atherosclerosis. ${ }^{7}$

\section{Materials and Methods}

We retrospectively studied 36 adult patients $(\mathrm{M} / \mathrm{F}$ : 21/15; age: $55 \pm 1.5$ years) diagnosed with metabolic syndrome (MetS) who underwent cardiac multidetector computed tomography (MDCT) for the calcium score evaluation. Patients were recruited at the Prevention of Cardiovascular Diseases ambulatory of 'Fatebenefratelli Hospital - Isola Tiberina'. According to the Adult Treatment Panel III (ATP III) report, the subjects were diagnosed with MetS in the presence of three or more of the following criteria: i) waist circumference higher or equal to $102 \mathrm{~cm}$ for men and $88 \mathrm{~cm}$ for women; ii) triglyceride levels higher or equal to $1.7 \mathrm{mmol} / \mathrm{L}$; iii) high-density lipoprotein cholesterol level less than $1.03 \mathrm{mmol} / \mathrm{L}$ or $1.29 \mathrm{mmol} / \mathrm{L}$ for men and women, respectively; iv) systolic blood pressure higher than, or equal to $130 \mathrm{mmHg}$, or diastolic blood pressure higher than or equal to $85 \mathrm{mmHg}$; v) fasting blood glucose higher than or equal to $6.1 \mathrm{mmol} / \mathrm{L}{ }^{8}$ 
The recruited patients were males and females aged between 45 and 75 years, affected by MetS (according to ATP III) but without diabetes (glycemia $\leq 126$ ). Our study excluded patients with renal impairment, previous cardiovascular events (ischemic heart disease, cerebrovascular disease) and history of cancer and/or diabetes, and women in pregnancy and/or breastfeeding. Moreover, to avoid selection bias, patients with a history of overt type 2 diabetes were excluded from the study. This study was carried out with the approval of the local ethics committee and the informed consent of all the participating patients.

\section{Computed tomography imaging}

Patients performed MDCT scans, according to the protocol generally used for calcium score. This method is a non-invasive approach for the research and quantification of EF (Figure 1). The imaging parameters for cardiac MDCT were: prospective sequential electrocardiogram gating; 64 channel detectors along the z-axis, scan FOV 15-21 cm (depending on the patient size), matrix $512 \times 512$, by means of axial scans detector collimation $3 \mathrm{~mm}$; reconstruction 2.5 $\mathrm{mm}$, gantry rotation time $0.25 \mathrm{~ms}$, tube 9 current range 50-100 $\mathrm{mA}$ (depending on the patient size and with automated modulation), $100 \mathrm{kV}$ or $120 \mathrm{kV}$ [according to body mass index (BMI)]. CT images were reconstructed with a slice thickness of $2.5 \mathrm{~mm}$ and a slice distance of $0.5 \mathrm{~mm}$ with an overlap of $0.5 \mathrm{~mm}$, both in the CAS and CTA images (Figure 2).

The epicardial fat was considered the adipose tissue accumulated between the visceral pericardium and the myocardium, without a structure or fascia separating it from the myocardium and the epicardial vessels. ${ }^{9}$ For the EF quantification, DICOM images were transferred to a research workstation. The epicardial surface was computed by using an interactive procedure previously developed at the CNR Institute of Clinical Physiology. The procedure required tracing the pericardial contours both in contiguous axial slices. Furthermore, the procedure allowed splitting the cardiac region into left and right zones by tracing an interventricular plane in two axial slices. In order to evaluate the correlation between individuals, every single cardiac silhouette and the subsequent volume were analyzed in a blinded fashion by two radiologists with four and ten years' experience on thorax CT imaging, respectively. We decided to calculate the EF quantity as a volumetric measurement, to obtain higher reproducibility and inter-observer agreement than a distance measurement. ${ }^{10}$

\section{Anthropometric measurements}

Body height was measured to the nearest $0.1 \mathrm{~cm}$ using a wall-mounted stadiometer. Body weight was measured to the nearest $0.01 \mathrm{~kg}$ using calibrated electronic digital scales in barefoot subjects. BMI was calculated by dividing the body weight (in kilograms) by height squared (in meters) and was used to quantify obesity. Waist circumference was measured at the level of the umbilicus with quiet respiration. The calculation of body surface area (BSA) was done using the Mosteller formula $([\text { Height }(\mathrm{cm}) \times \text { Weight }(\mathrm{kg})] / 3600)^{(1 / 2)} .^{11}$

\section{Blood pressure}

Blood pressure (systolic and diastolic) was measured, in the sitting position, after a 20 -min rest period using a mercury manometer. We calculated the average value originated from two different measurements.

\section{Biochemical analysis}

Blood exams were put into 8-mL tubes containing thrombin- and heparin-neutralizing agents. Blood was

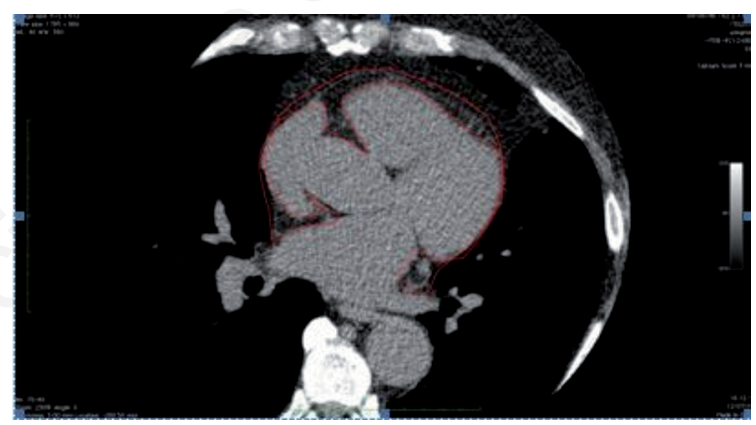

Figure 1. Epicardial fat on axial computed tomography images of the heart.

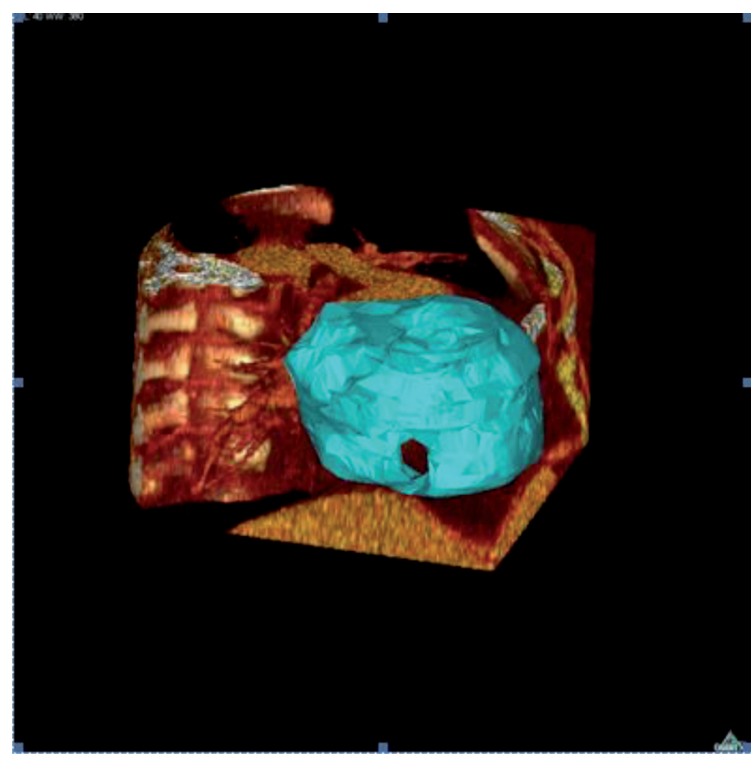

Figure 2. Measurement of epicardial fat volume: 3D reconstruction. 
centrifuged at $3000 \mathrm{rpm}$ for $30 \mathrm{~min}$ at $4^{\circ} \mathrm{C}$ to separate plasma. High-density lipoprotein cholesterol and triglyceride levels were determined in serum through the semiautomatic chemical analyzer Ekem Control Lab. The blood glucose level was measured using Cobas c111 automated chemistry analyzer (Roche Diagnostics $\mathrm{GmbH}$, Mannheim, Germany) in vitro test kits for the qualitative test of human serum and plasma. Plasma TG concentrations were determined by means of the enzymatic method using a TG kit, and plasma-free fatty acids were measured by the colorimetric method. CRP was measured using a sensitive double-antibody sandwich ELISA with rabbit antihuman CRP and peroxidase-conjugated rabbit antihuman CRP. The assay was linear up to $5 \mathrm{mg} / \mathrm{L}$ and logarithmic thereafter. The inter-assay and intra-assay coefficients of variation were $<10 \%$ across the range of measured results. Low-density lipoprotein-cholesterol was calculated by Friedewald's formula. ${ }^{12}$

\section{Statistical analysis}

Statistical comparisons between groups (men and women) were performed using Student's $t$-test for two samples or Mann-Whitney U test for parametric or non-normally distributed data (Kolmogorov-Smirnov test), respectively. Unequal-Variance test was used when the variances of the two populations were not equal to the Aspin-Welch. Correlations between serum CRP levels and other variables were determined using Spearman's (rs) and Pearson's (rp) r correlation, while multivariate relationships were analyzed using multiple regression models. Data are shown as mean \pm standard error mean or median $\left(25^{\text {th }}\right.$ percentile; $75^{\text {th }}$ percentile). $\mathrm{P}<0.05$ were considered to indicate statistical significance. Statistical analysis was carried out using the NCSS software (Kaysville, UT, USA). ${ }^{13}$

\section{Results}

A total of 36 patients were evaluated, and we have classified the patients into two groups: men and women. $26.6 \%$ satisfied three criteria among women, and $50 \%$ of them had blood glucose $>100 \mathrm{mg} / \mathrm{dL}$. In $73.4 \%$ of cases, there were more than three criteria satisfied, and $33 \%$ had blood glucose values greater than $100 \mathrm{mg} / \mathrm{dL}$. Among men, three metabolic syndrome diagnostic criteria were present in $22 \%$ of cases (there was an alteration in glucose control in $25 \%$ of cases), whereas the other patients (78\%) had more than three diagnostic criteria (blood glucose $>100 \mathrm{mg} / \mathrm{dL}$ were $33 \%)$. This distribution was homogeneous. The mean age of patients was $59.3 \pm 10.79$ years, and $58.3 \%$ of the subjects were male. The average values of EF were $115.1 \mathrm{cc}$ in the study population. The average EF of women was $111 \mathrm{cc}$; the average EF of men was $118 \mathrm{cc}$ $(\mathrm{P}=0.18)$ (Figure 3$)$. The main clinical and laboratory findings of the 2 groups were summarized in Table 1.

There was no significant difference between the Men and the Women group for BMI, waist circumference, blood pressure, fasting blood glucose, insulin levels, lipids, uric acid concentrations, smoking habit, and age.

The median levels of C-reactive protein were 2.71 $\mathrm{mg} / \mathrm{L}$ in women compared with $1.74 \mathrm{mg} / \mathrm{L}$ in men

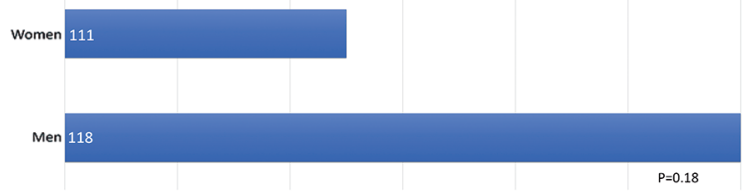

Figure 3. Epicardial fat measures in men and women (cc).

Table 1. Principal characteristics of the study population.

\begin{tabular}{lccc}
\hline & Men & Women & P \\
\hline Age $(\mathrm{yrs})$ & $57(54 ; 61)$ & $59(54 ; 66)$ & $\mathrm{ns}$ \\
\hline Waist circumference $(\mathrm{cm})$ & $105(101 ; 110)$ & $101(100 ; 115)$ & $\mathrm{ns}$ \\
\hline BPs $(\mathrm{mmHg})$ & $140(130 ; 147)$ & $143(140 ; 145)$ & $\mathrm{ns}$ \\
\hline BPd $(\mathrm{mmHg})$ & $84(81 ; 91)$ & $91(90 ; 95)$ & $\mathrm{ns}$ \\
\hline Triglycerides $(\mathrm{mmol} / \mathrm{L})$ & $1.5(1.12 ; 1.9)$ & $2.12(1.52 ; 2.2)$ & $\mathrm{ns}$ \\
\hline Glucose $(\mathrm{mmol} / \mathrm{L})$ & $5.1(4.3 ; 5.8)$ & $5.12(4,8 ; 5.78)$ & $\mathrm{ns}$ \\
\hline HDL $(\mathrm{mmol} / \mathrm{L})$ & $1.03(0.96 ; 1.27)$ & $1,03(0.97 ; 1.27)$ & $\mathrm{ns}$ \\
\hline Epicardial fat $(\mathrm{ml})$ & $118(91.7 ; 129.8)$ & $111(106 ; 150)$ & $\mathrm{ns}$ \\
\hline HbA1c $(\mathrm{mmol} / \mathrm{mol})$ & $42(31 ; 48)$ & $40(35 ; 60)$ & $\mathrm{ns}$ \\
\hline Insulin $(\mathrm{pmol} / \mathrm{L})$ & $80.7 \pm 8.8$ & $85.9 \pm 15.2$ & $\mathrm{~ns}$ \\
\hline Uric acid $(\mu \mathrm{mol} / \mathrm{L})$ & $52 \pm 3.4$ & $59.8 \pm 4.2$ & $\mathrm{~ns}$
\end{tabular}

Data are mean \pm standard error mean or median $\left(25^{\text {th }}\right.$ percentile; $75^{\text {th }}$ percentile). BPs, systolic blood pressure; BPd, diastolic blood pressure; HDL, high-density lipoproteins; ns, not significant. 
$(\mathrm{P}=0.002)$ (Figure 4). Pearson's correlation showed a strong, positive correlation between epicardial fat obtained from MDCT and HS-CRP in women $(\mathrm{r}=0.426$ $\mathrm{P}<0.01)$, but not in men $(\mathrm{r}=0.142 \mathrm{P}=0.4)$ (Table 2). No differences between premenopausal and postmenopausal women were observed.

\section{Discussion}

$\mathrm{EF}$ is now considered an independent risk factor for cardiovascular risk due to its capacity to secrete a number of cytokines and chemokines. These molecules, known as adipokines, are produced from mature adipocytes and from the cells present within the adipose tissue (macrophages, fibroblasts, mast cells) and are correlated to the development of coronary atherosclerosis. ${ }^{14,15}$ In pathological conditions, such as those found in patients with MetS, the EF undergoes many changes causing the invasion of macrophages and $\mathrm{T}$ lymphocytes in the adipose tissue. ${ }^{16,17}$ Consequently, there is an increased secretion of pro-inflammatory cytokines and a reduction in the secretion of anti-atherosclerotic adipokines such as adiponectin. These modifications are related to the development of atherosclerosis and changes in plaque phenotype. ${ }^{18} \mathrm{CRP}$ is an acute-phase reactant that is a marker of inflammation in the body, and elevations of CRP concentrations are risk factors predictive of future cardiovascular events. ${ }^{19} \mathrm{~A}$ high CRP value results to be a marker of increase in IL-6. IL-6 plays a vital role in the development of atherosclerosis, through the activation of endothelial cells and the coagulation cascade and the proliferation of lymphocyte and the activation of the local renin-angiotensin pathways, and this promotes vascular wall inflammation and damage. ${ }^{20}$

In addition, the increase in CRP may directly enhance inflammation in plaques, mediated binding to the complement factor $\mathrm{C} 1 \mathrm{q}$, and through the direct activation of different adhesion molecules. ${ }^{21,22}$ Previous

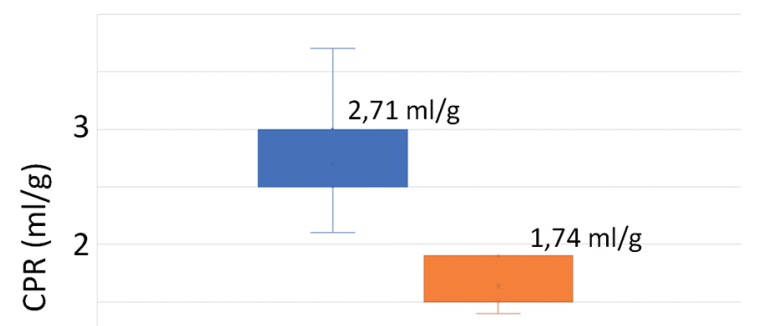

1

\footnotetext{
Women

Men

Figure 4. C-reactive protein (CRP) values in the men and women group.
}

studies had already shown an association between CRP levels and visceral adipose tissue..$^{23,24}$ The reason for this correlation was identified in overproduction, by adipocytes, tumor necrosis factor messenger RNA (TNF-alpha). TNF-alpha induces IL-6 synthesis, which modulates the production of CRP. ${ }^{25,26}$ In our study, we noted strong correlations between EF and CRP in the Women group only. A possible explanation for this result might be that the metabolic activity of adipose tissue is different in men and women due to the influence of sex steroids, which leads to a different response in the production of inflammation mediators. ${ }^{27}$ Some experimental data suggest an inhibitory effect of estrogens on interleukin 6 gene expression, while some authors have suggested an increase in CRP with hormone replacement therapy (no patients recruited in our study, however, took on replacement therapy). ${ }^{28-30}$ Anyway, although many studies show that estrogens play an important role in decreasing visceral fat, it is still unclear the role of sex hormones in the epicardial fat with unique specificity. ${ }^{31,32}$ Gender differences are confirmed by other studies showing that the EF produces higher adiponectin concentrations and leptin in women than in men. ${ }^{33}$

Furthermore, our data found that the average abdominal circumference in the female population exceeds the basic values according to ATP III (101 vs 88 $\mathrm{cm})$ than in the male population (105 vs $102 \mathrm{~cm}$ ), although it is not statistically significant. Probably, that is due to the hormonal changes that occur with menopause, characterized by a reduction in estrogen (responsible for the accumulation of fat in the subcutaneous tissue, in particular in the gluteal and femoral regions), and by a relative increase in androgens (which instead promote the accumulation of fat in the abdomen). Consequently, the relative hyperandrogenism observed in menopause, caused by the decline in estrogen, becomes the cause of metabolically unfavorable fat redistribution prevalent in the abdominal area. On the one hand, this reflection allows us to interpret the results of our work better; on the other hand, it leads us to propose the introduction of a corrective measure for the age group that is useful for women, for the measurement of the waist, which includes at least a pre and postmenopausal cut-off. The metabolically unfavorable redistribution of fat prevalent in the abdominal area can also determine a higher value of

Table 2. Correlation of high sensitivity $C$-reactive protein with percentage epicardial fat area in subjects with metabolic syndrome.

\begin{tabular}{lcl}
\hline Epicardial fat area & $\begin{array}{c}\text { Men } \\
(\mathbf{n}=\mathbf{2 2})\end{array}$ & $\begin{array}{c}\text { Women } \\
(\mathbf{n}=\mathbf{1 4})\end{array}$ \\
\hline hs-CRP & 0.209 & $0.360^{*}$ \\
\hline
\end{tabular}

Values are correlation coefficients, ${ }^{*} \mathrm{P}<0.01$ hs-CRP, high sensitivity C-reactive protein. 
triglyceridemia, as we found in the female sample, always in a not statistically significant way. In this last regard, it should also be emphasized that compared to measuring the waist, the triglyceridemia values are extremely variable and more difficult to read. Moreover, sex-specific adipose tissue distribution also may result from the secretion of sex hormones produced by adipose tissue itself. These data suggest that the role of sex hormones may have fundamental effects on the metabolic activity of epicardial fat.

\section{Study limitations}

This study has some limitations: the retrospective and cross-sectional nature of the survey does not allow conclusions to be drawn about the actual prognostic values and the molecular mechanisms underlying the relationships between EF, and CRP. Moreover, the small sample size may partly explain the lack of differences between groups (type I error).

\section{Conclusions}

The present study demonstrates that women patients affected by metabolic syndrome exhibit a significant increase in CRP levels, at $\mathrm{EF}$ equal, compared to men ones. Being recognized now EF as an independent cardiovascular risk factor, our study suggests that the pro-inflammatory coronary state can be increased in women, resulting in an increased risk of atherosclerosis development. Further studies are necessary to elucidate the true importance of the different activities of the sex-related epicardial fat. Determining the expression of steroidogenic metabolizing enzymes, different receptors of the EF behavior, and the expression of inflammatory proteins will allow us to understand better the mechanisms of the epicardial fat in the pathogenesis of atherosclerosis.

\section{References}

1. Weisberg SP, McCann D, Desai M, et al. Obesity is associated with macrophage accumulation in adipose tissue. J Clin Invest 2003;112:1796-808.

2. Xu H, Barnes GT, Yang Q, et al. Chronic inflammation in fat plays a crucial role in the development of obesity-related insulin resistance. J Clin Invest 2003;112:1821-30.

3. Mohamed-Ali V, Goodrick S, Rawesh A, et al. Subcutaneous adipose tissue releases interleukin-6, but not tumor necrosis factor- $\alpha$, in vivo. J Clin Endocrinol Metab 1997;82:4196-200.

4. Corradi D, Maestri R, Callegari S, et al. The ventricular epicardial fat is related to the myocardial mass in normal, ischemic and hypertrophic hearts. Cardiovasc Pathol 2004;13:313-6.

5. Iacobellis G, Malavazos AE, Corsi MM. Epicardial fat: from the biomolecular aspects to the clinical practice.
Int J Biochem Cell Biol 2011;43:1651-4.

6. Chen X, Jiao Z, Wang L, et al. Roles of human epicardial adipose tissue in coronary artery atherosclerosis. J Huazhong Univ Sci Technolog Med Sci 2010; 30:589-93.

7. Monti M, Monti A, Murdolo G, et al. Correlation between epicardial fat and cigarette smoking: CT imaging in patients with metabolic syndrome. Scand Cardiovasc J 2014;48:317-22.

8. Al-Delaimy WK, Willett WC, Manson JE, et al. Smoking and mortality among women with type 2 diabetes: the Nurses' Health Study cohort. Diabetes Care 2001;24:2043-8

9. Dey D, Nakazato R, Li D, Berman SD. Epicardial and thoracic fat - Noninvasive measurement and clinical implications. Cardiovasc Diagn Ther 2012;2:85-93.

10. Flüchter S, Haghi D, Dinter D, et al. W Volumetric assessment of epicardial adipose tissue with cardiovascular magnetic resonance imaging. Obesity (Silver Spring) 2007; 15:870-8.

11. Mosteller RD. Simplified calculation of body-surface area. N Engl J Med 1987;317:1098.

12. Friedewald WT, Levy RI, Fredrickson DS. Estimation of the concentration of low-density lipoprotein cholesterol in plasma, without use of the preparative ultracentrifuge. Clin Chem 1972;18,499-502.

13. Bland JM, Altman DG Statistical methods for assessing agreement between two methods of clinical measurement. Lancet 1986;8:307-10.

14. Shioji K, Moriguchi A, Moriwaki S, et al. Hypoadiponectinemia implies the development of atherosclerosis in carotid and coronary arteries. J Cardiol 2005;46:105-12.

15. Libby P, Ridker PM, Maseri A. Inflammation and atherosclerosis. Circulation 2002;105:1135-43.

16. Greenstein AS, Khavandi K, Withers SB, et al. Local inflammation and hypoxia abolish the protective anticontractile properties of perivascular fat in obese patients. Circulation 2009;119:1661-70.

17. Greif M, Becker A, von Ziegler F, et al. Pericardial adipose tissue determined by dual source $\mathrm{CT}$ is a risk factor for coronary atherosclerosis. Arterioscler Thromb Vasc Biol 2009;29:781-6.

18. Salgado-Somoza A, Teijeira-Fernández E, Rubio J, et al. Coronary artery disease is associated with higher epicardial retinol-binding protein 4 (RBP4) and lower glucose transporter (GLUT) 4 levels in epicardial and subcutaneous adipose tissue. Clin Endocrinol (Oxf) 2012;76:51-8.

19. Ridker PM, Buring JE, Shih J, et al. Prospective study of C-reactive protein and the risk of future cardiovascular events among apparently healthy women. Circulation 1998;98:731-3.

20. Hartman J, Frishman WH. Inflammation and atherosclerosis: a review of the role of interleukin- 6 in the development of atherosclerosis and the potential for targeted drug therapy. Cardiol Rev 2014;22:147-51.

21. Burke AP, Tracy RP, Kolodgie F et al. Elevated C-reactive protein values and atherosclerosis in sudden coronary death: association with different pathologies. Circulation 2002;105:2019-23.

22. Pasceri V, Chang J, Willerson JT et al. Modulation of Creactive protein-mediated monocyte chemoattractant 
protein-1 induction in human endothelial cells by antiatherosclerosis drugs. Circulation 2001;103:2531-4.

23. Després JP, Pascot A, Bergeron J, et al. Abdominal obesity: the critical correlate of elevated plasma C-reactive protein levels associated with features of the insulin resistance syndrome in men. Atherosclerosis 2000;151:98.

24. Saijo Y, Kiyota N, Kawasaki Y, et al. Relationship between $\mathrm{C}$ reactive protein and visceral adipose tissue in healthy Japanese subjects. Diabetes Obes Metab 2004;6:249-58.

25. Danesh J, Collins R, Appleby P, et al. Association of fibrinogen, C-reactive protein, albumin, or leukocyte count with coronary heart disease: meta-analyses of prospective studies. JAMA 1998;279:1477-82.

26. Pérez-Segura P, de Dios O, Herrero L, et al. Children with type 1 diabetes have elevated high-sensitivity Creactive protein compared with a control group. BMJ Open Diabetes Res Care 2020;8:e01424.

27. Miyazawa I, Ohkubo T, Kadowaki S, et al. Change in pericardial fat volume and cardiovascular risk factors in a general population of Japanese men. Circ J 2018;82:2542-8.

28. Hak AE, Stehouwer CD, Bots ML, et al. Associations of C-reactive protein with measures of obesity, insulin resistance, and subclinical atherosclerosis in healthy, middle-aged women. Arterioscler Thromb Vasc Biol 1999;19:1986-91.

29. Ray P, Ghosh SK, Zhang DH, et al. Repression of interleukin-6 gene expression by 17 inhibition of the DNAbinding activity of the transcription NF-IL6 and NF-kappa B by the estrogen receptor. FEBS Lett 1997;409:79-85.

30. Van Baal WM, Kenemans P, van der Mooren MJ, et al. Increased C-reactive protein levels during short-term hormone replacement therapy in healthy postmenopausal women. Thromb Haemost 1999; 81:925-8

31. White UA, Tchoukalova YD. Sex dimorphism and depot differences in adipose tissue function. Biochim Biophys Acta 2014;1842:377-92.

32. Iacobellis G, Malavazos AE, Corsi MM. Epicardial fat: from the biomolecular aspects to the clinical practice. Int J Biochem Cell Biol 2011;43:1651-4.

33. Gruzdeva O, Uchasova E, Dyleva Y, et al. Adipocytes directly affect coronary artery disease pathogenesis via induction of adipokine and cytokine imbalances. Front Immunol 2019;10:2163. 